\title{
Макєঠovıкá
}

Tóp. 4, Ap. 1 (1960)

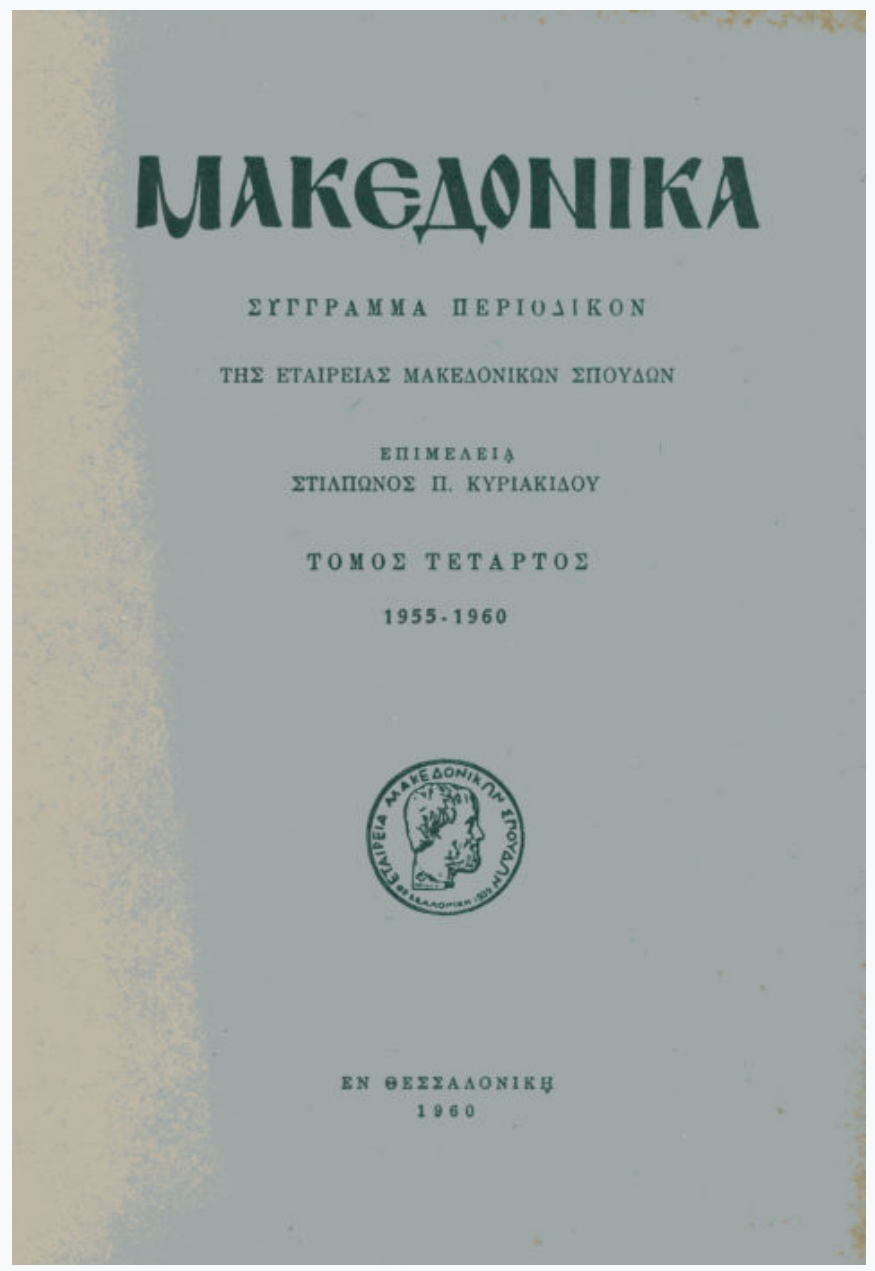

\section{Syndey Loch, The Holy Mountain}

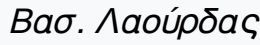

doi: $10.12681 /$ makedonika.734

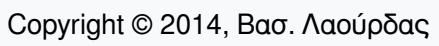

\section{(@) $\odot \Theta(\odot)$}

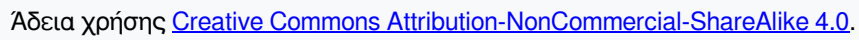

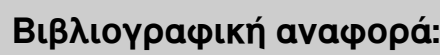

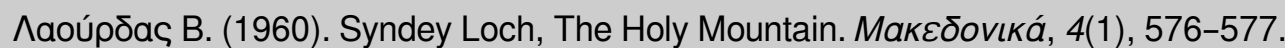

https://doi.org/10.12681/makedonika.734 


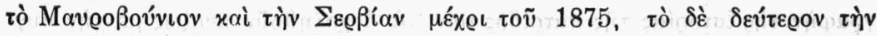

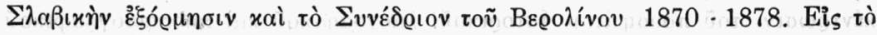

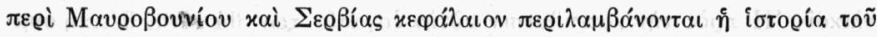

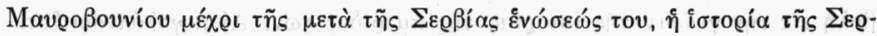

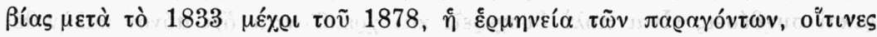

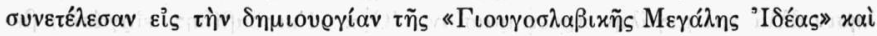

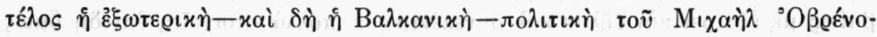

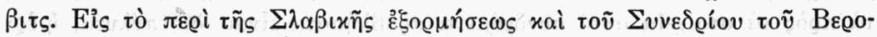

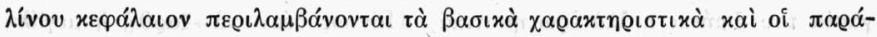

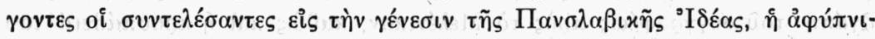

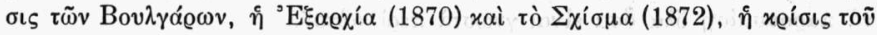

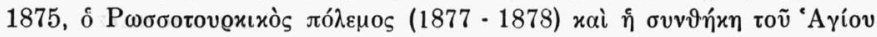

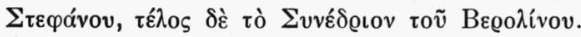

BAE. NAOYPAAE

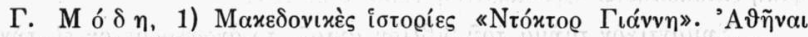

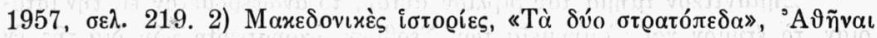

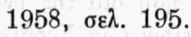

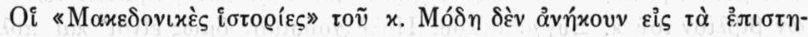

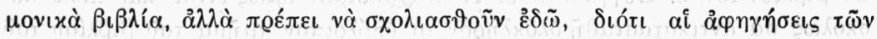

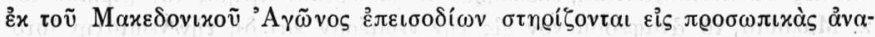

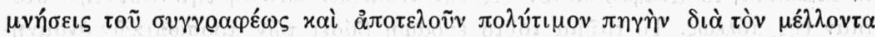

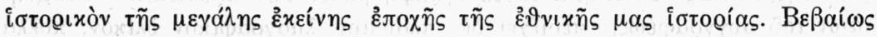

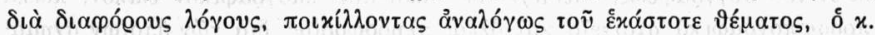

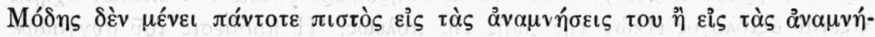

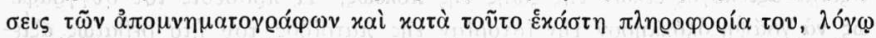
זท̃

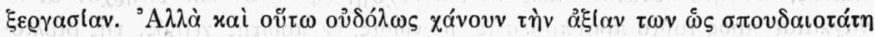

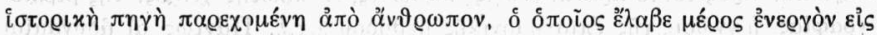

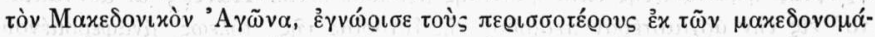

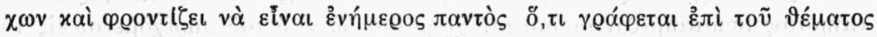

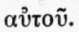

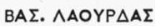

S y d n e y L o c h, The Holy Mountain, London 1957, $\sigma \varepsilon \lambda, 264$,

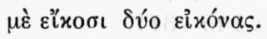

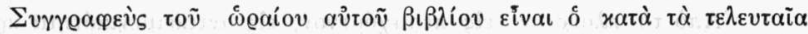

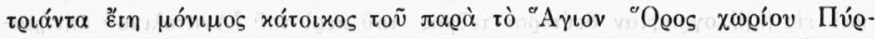

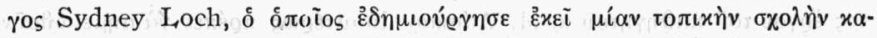

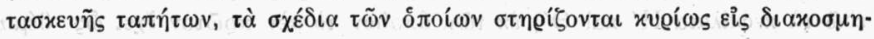




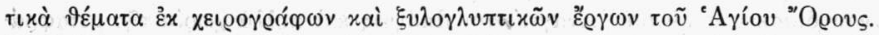

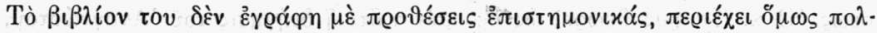

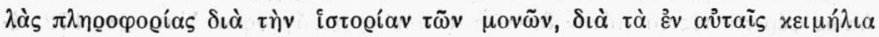

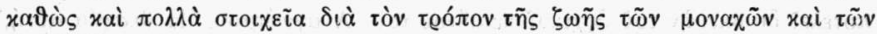

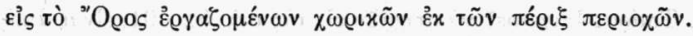

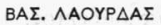

E manuel Amand de Mendieta, Le mont Athos. La

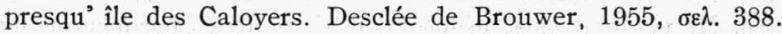

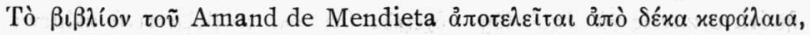

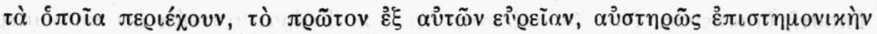

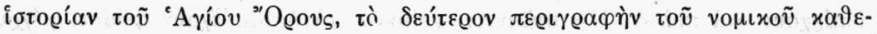

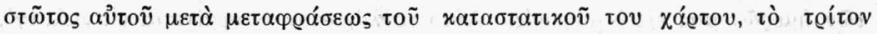

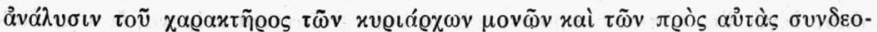

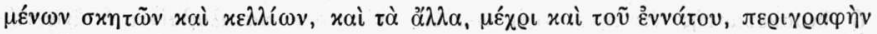

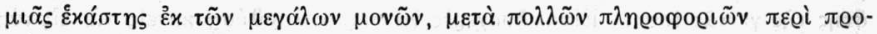

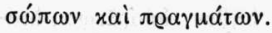

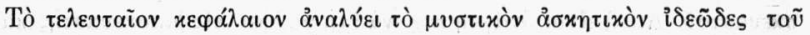

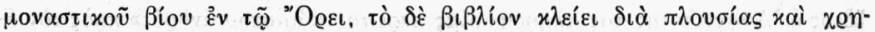

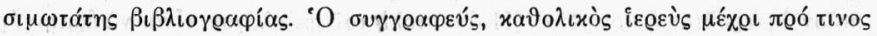

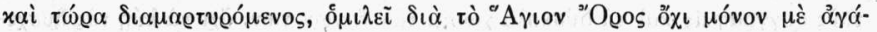

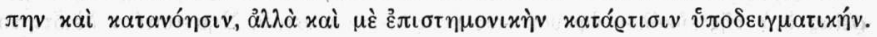

BAE. NAOYPAAE

$\mathrm{B} \iota \beta \lambda \iota 0 \vartheta \dot{\eta} x \eta \tau \tilde{\eta} \varsigma \mathrm{B} v \zeta \alpha v \tau \iota v \tilde{\eta} \varsigma \quad \Theta \varepsilon \sigma \sigma \alpha \lambda \circ v i x \eta \varsigma$.

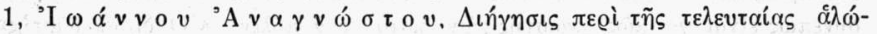

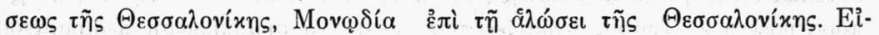

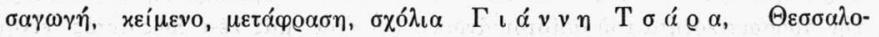
víx 1958, $\sigma \varepsilon \lambda . \lambda \alpha^{\prime}+104$.

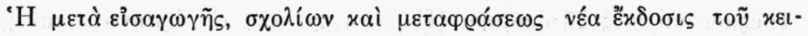

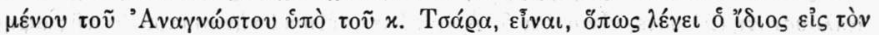

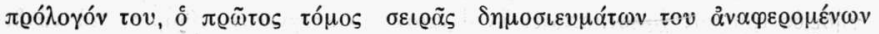

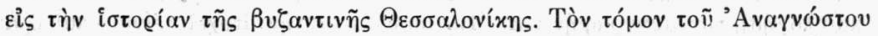

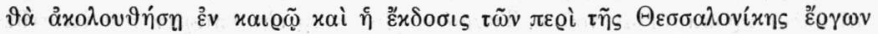

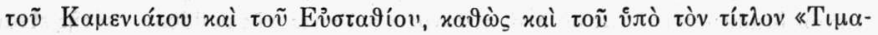

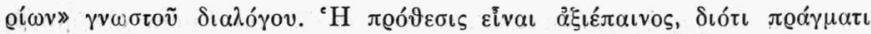

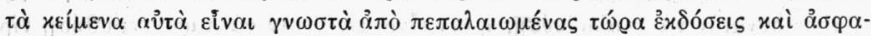

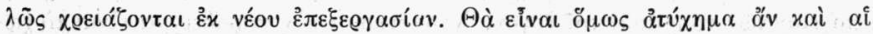

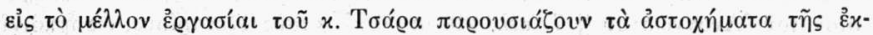

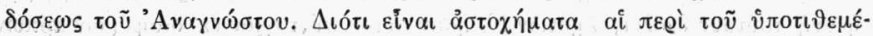

